Supporting information

\title{
Bioconjugation with Aminoalkylhydrazine for Efficient Mass Spectrometry-Based Detection of Small Carbonyl Compounds
}

Senthil K. Thangaraj, ${ }^{1}$ Sanni Voutilainen, ${ }^{2}$ Martina Andberg, ${ }^{2}$ Anu Koivula, ${ }^{2}$ Janne Jänis, ${ }^{1}$ and Juha Rouvinen ${ }^{l} *$

${ }^{1}$ Department of Chemistry, University of Eastern Finland, PO BOX 111, FI-801101 Joensuu, Finland

${ }^{2}$ VTT Technical Research Centre of Finland Ltd, PO Box 1000, FI-020444 VTT, Espoo, Finland

*Corresponding author: juha.rouvinen@uef.fi 


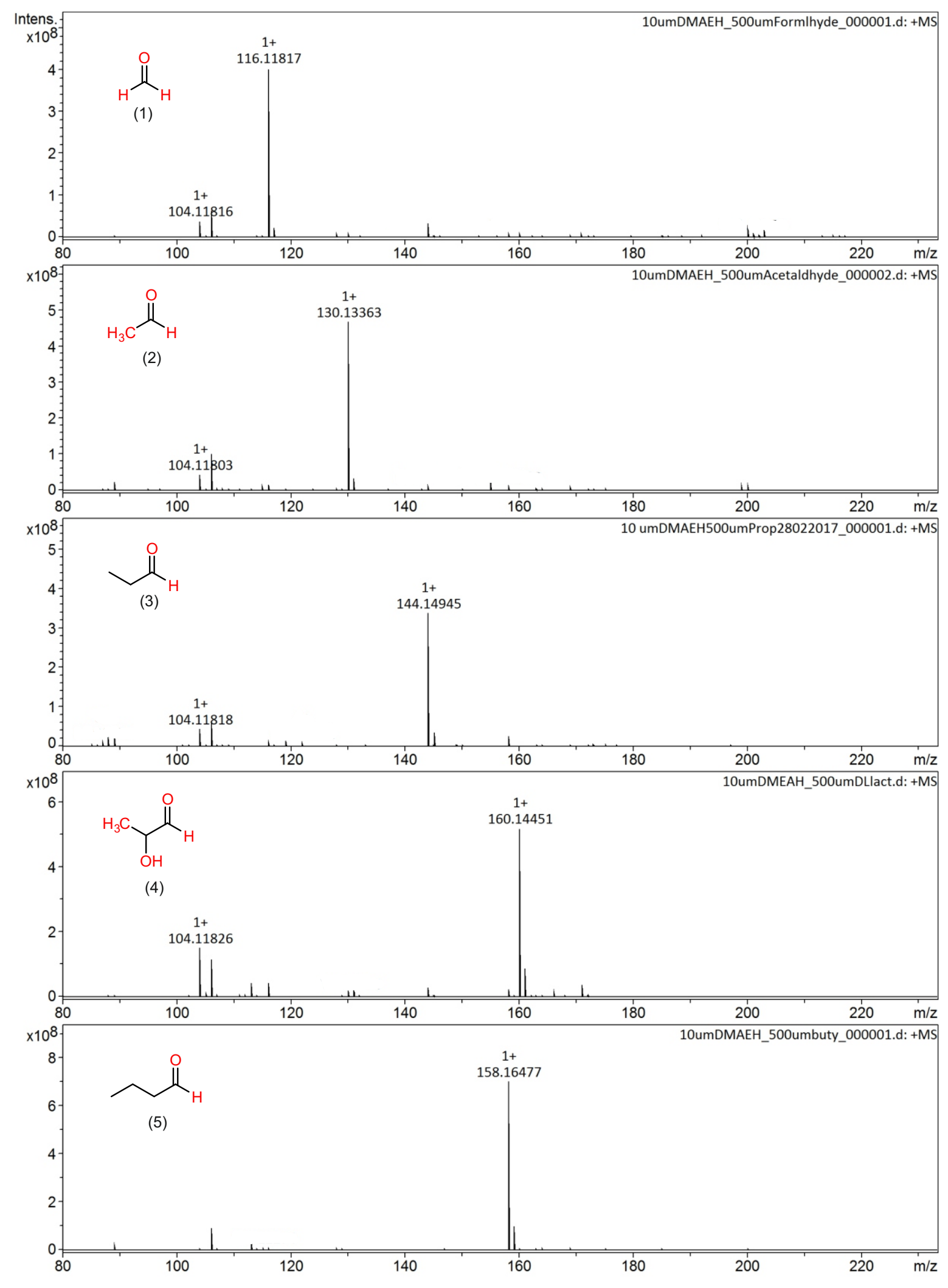

Figure S1. ESI FT-ICR mass spectra of hydrazone conjugate between DMAEH $(10 \mu \mathrm{M})$ and $\sim 50$-fold molar excess of aldehydes (1-5) in methanol solution. 


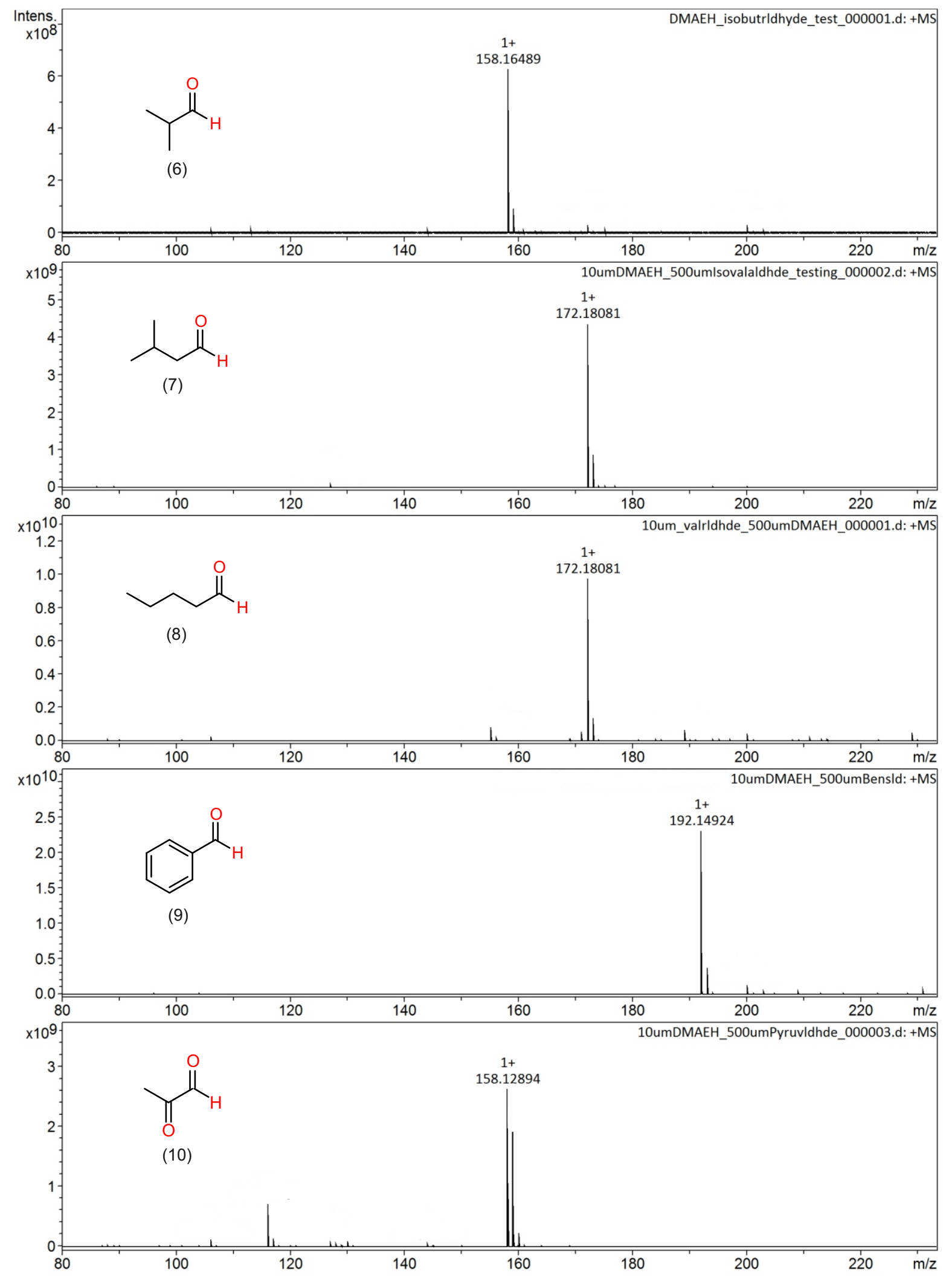

Figure S2. ESI FT-ICR mass spectra of hydrazone conjugate between DMAEH (10 $\mu \mathrm{M})$ and $\sim 50$-fold molar excess of aldehydes (6-10) in methanol solution. 


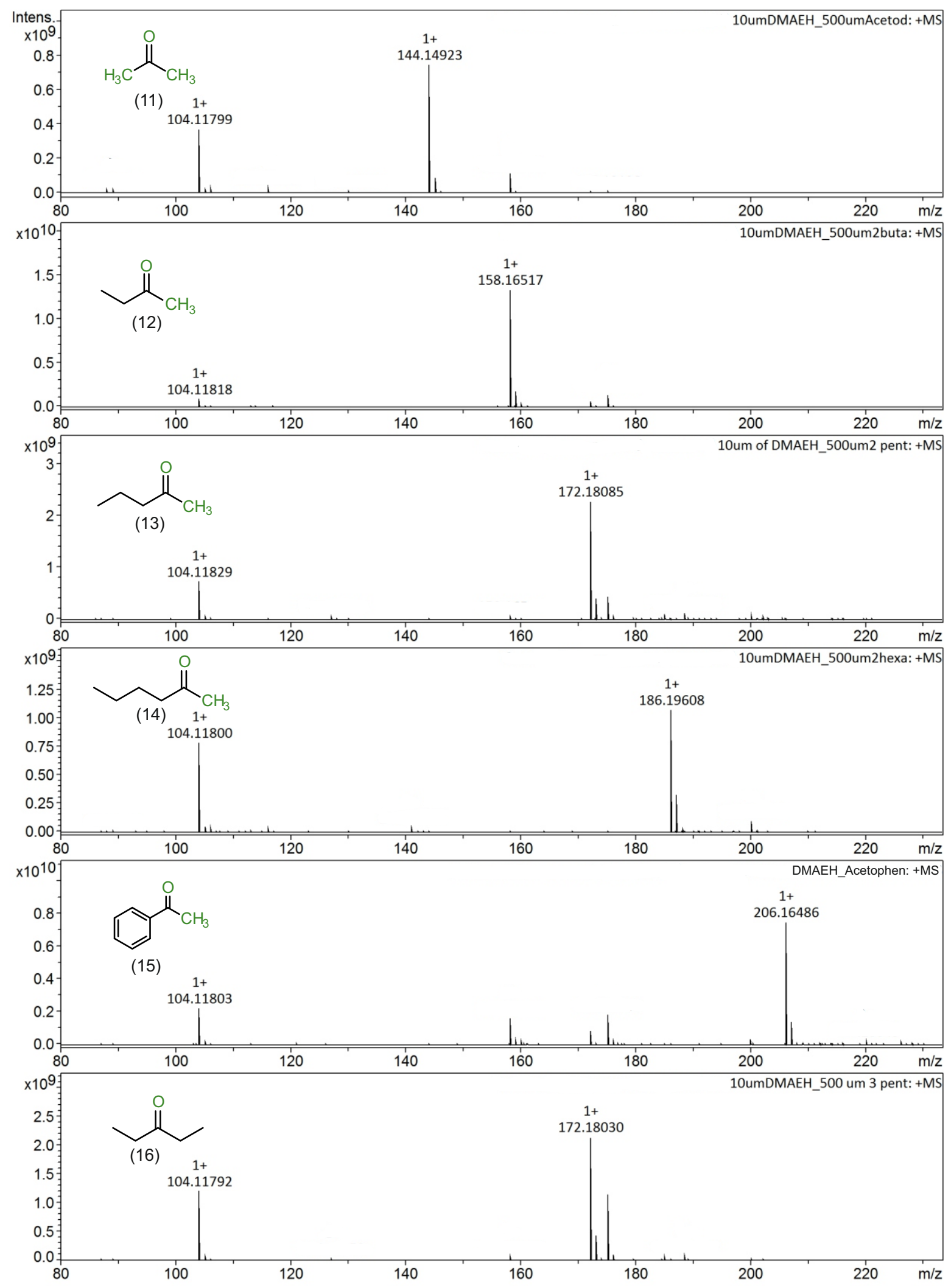

Figure S3. ESI FT-ICR mass spectra of hydrazone conjugate between DMAEH (10 $\mu \mathrm{M})$ and $\sim 50$-fold molar excess of ketones (11-16) in methanol solution. 


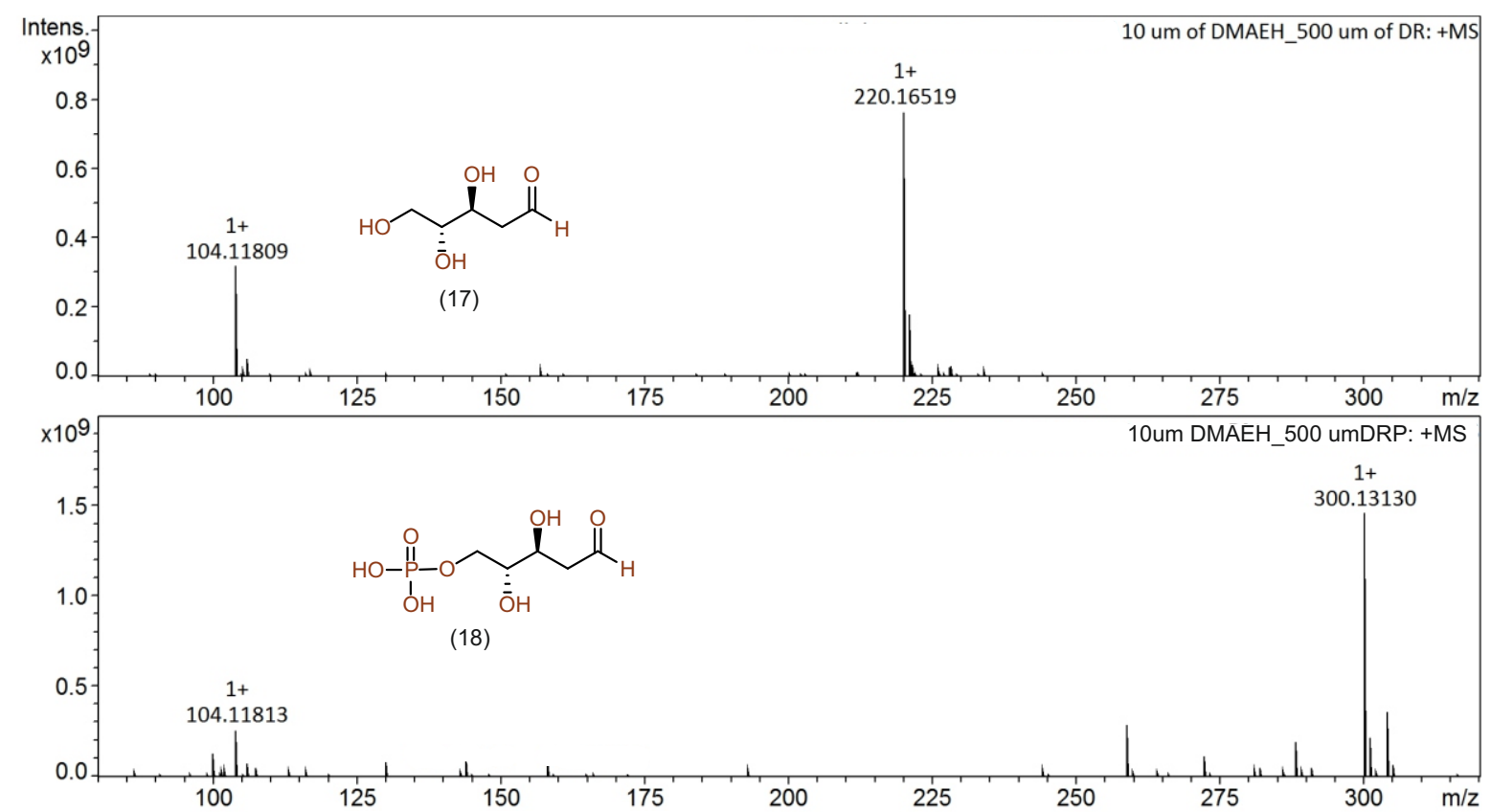

Figure S4. ESI FT-ICR mass spectra of hydrazone conjugate between DMAEH (10 $\mu \mathrm{M})$ and $\sim 50$-fold molar excess of sugars (17-18) in methanol solution. 

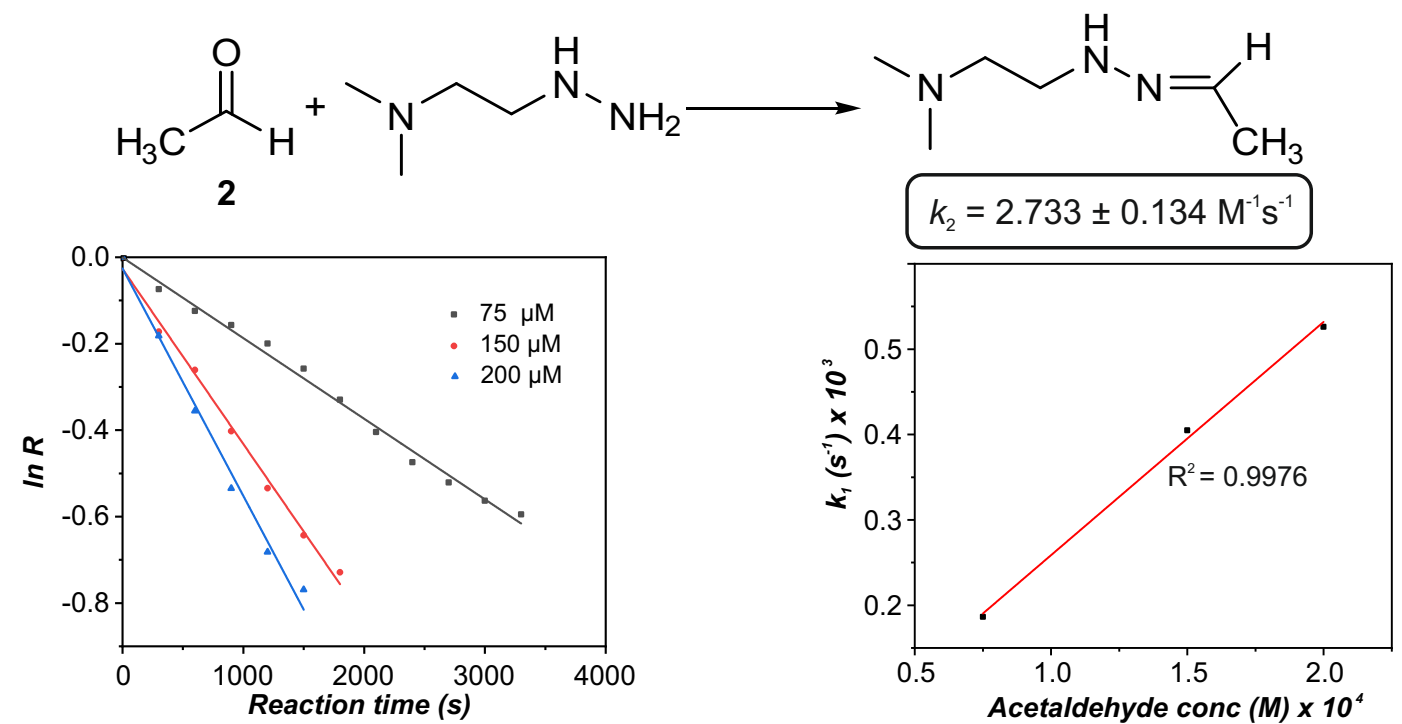

Figure S5. The pseudo first order (Log R vs time) and second order plot ( $k_{1}$ vs [CC]) of the hydrazone conjugation reactions of DMAEH with acetaldehyde (2).
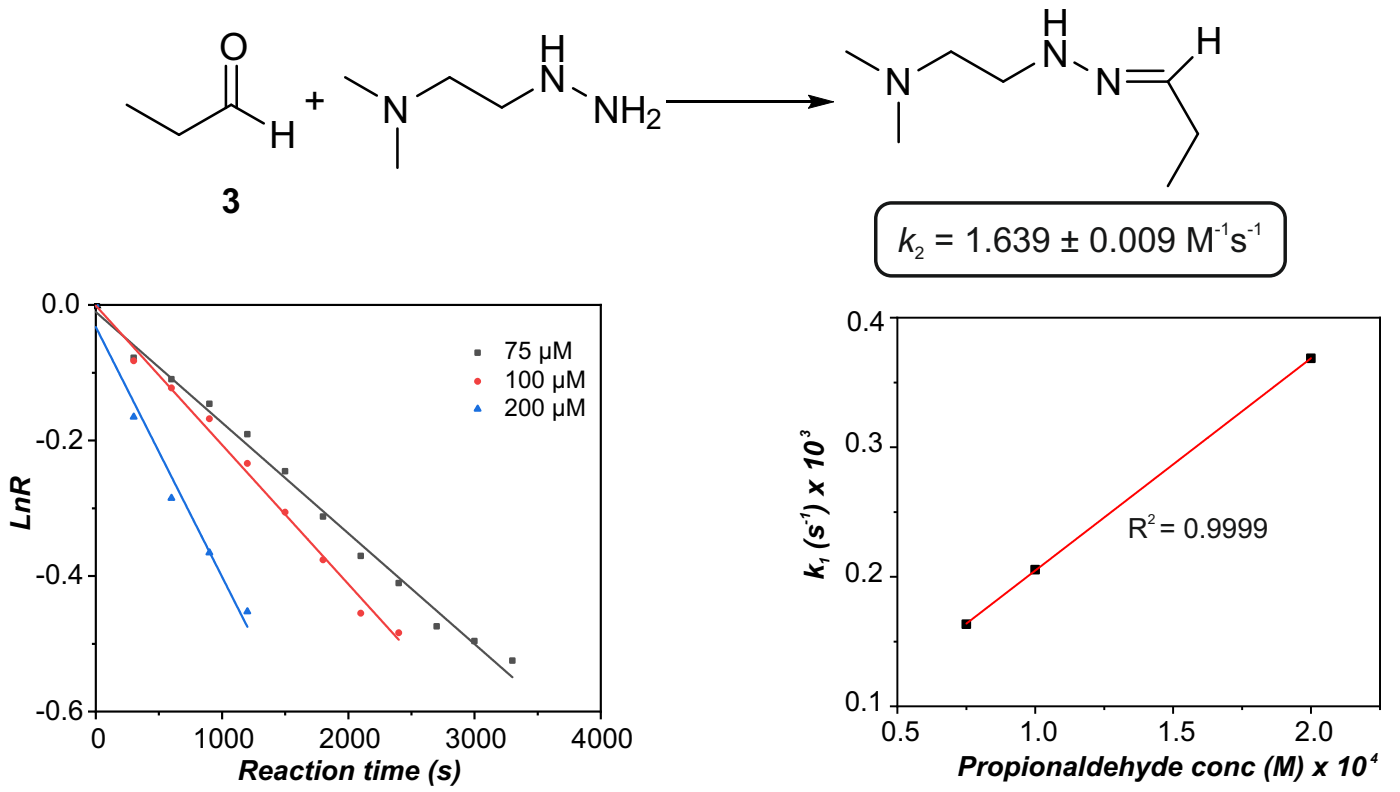

Figure S6. The pseudo first order (Log R vs time) and second order plot ( $k_{1}$ vs [CC]) of the hydrazone conjugation reactions of DMAEH with propionaldehyde (3).
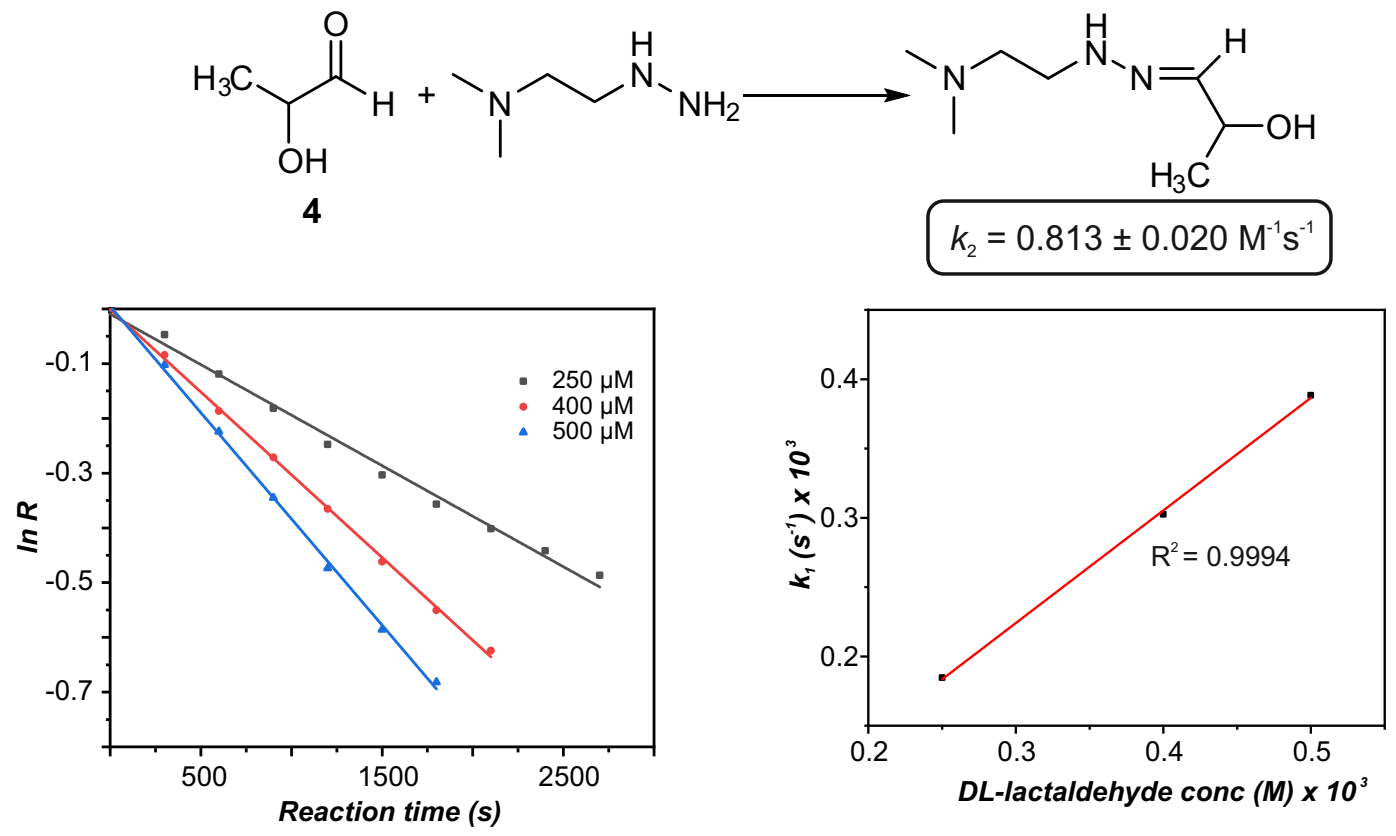

Figure S7. The pseudo first order (Log R vs time) and second order plot ( $k_{1}$ vs [CC]) of the hydrazone conjugation reactions of DMAEH with DL-lactaldehyde (4). 

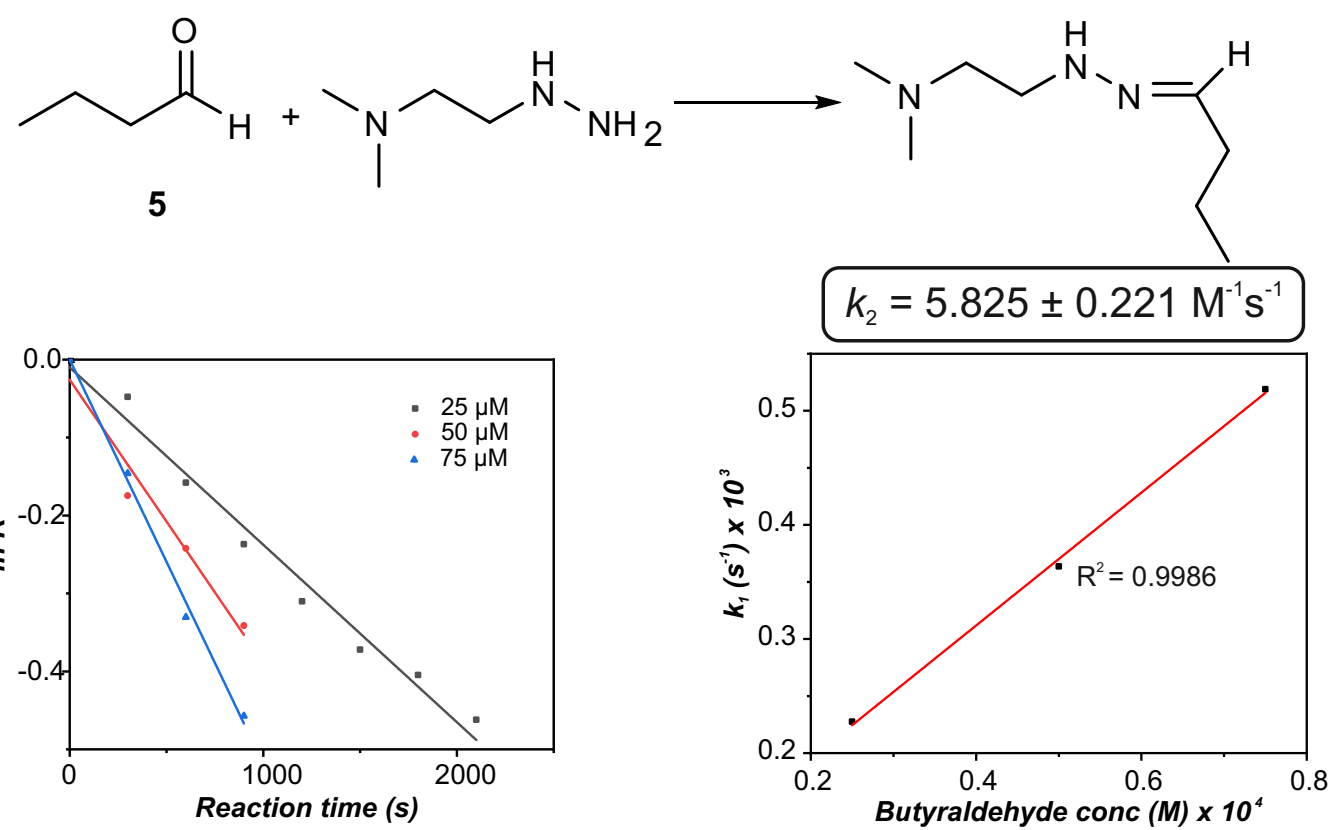

Figure S8. The pseudo first order (Log R vs time) and second order plot ( $k_{1}$ vs [CC]) of the hydrazone conjugation reactions of DMAEH with butyraldehyde (5).<smiles>CC(C)C(=O)[CH+]CN(C)CCNN</smiles>
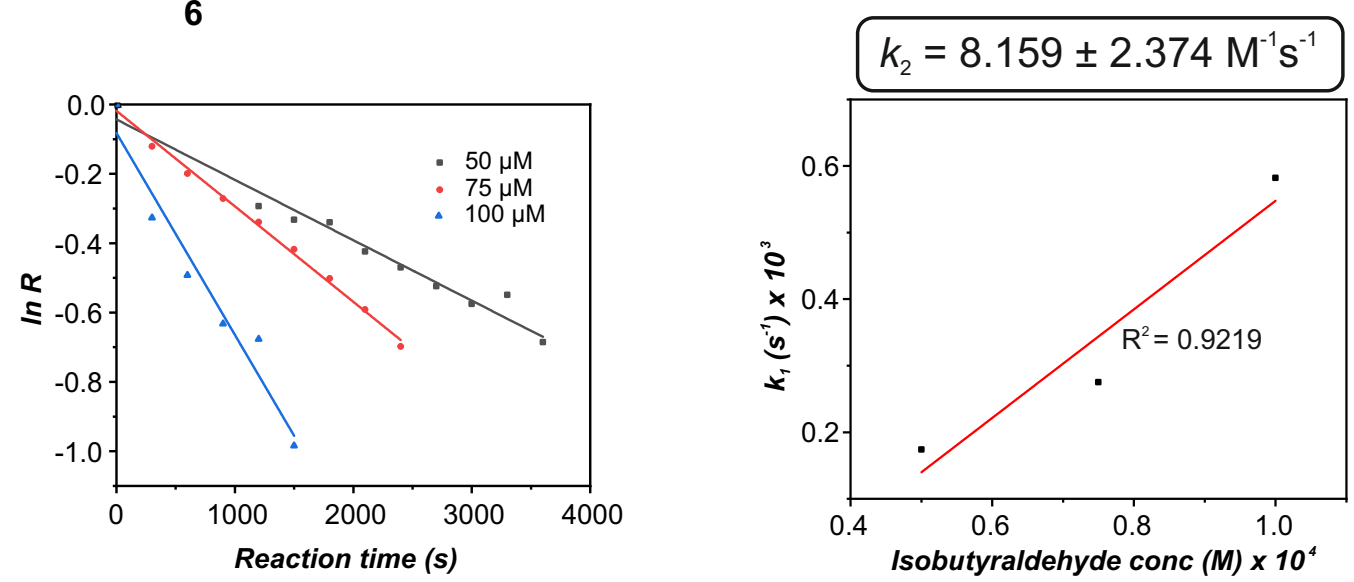

Figure S9. The pseudo first order (Log R vs time) and second order plot ( $k_{1}$ vs [CC]) of the hydrazone conjugation reactions of DMAEH with isobutyraldehyde (6).<smiles>CC(C)CC=NNCCN(C)C</smiles>
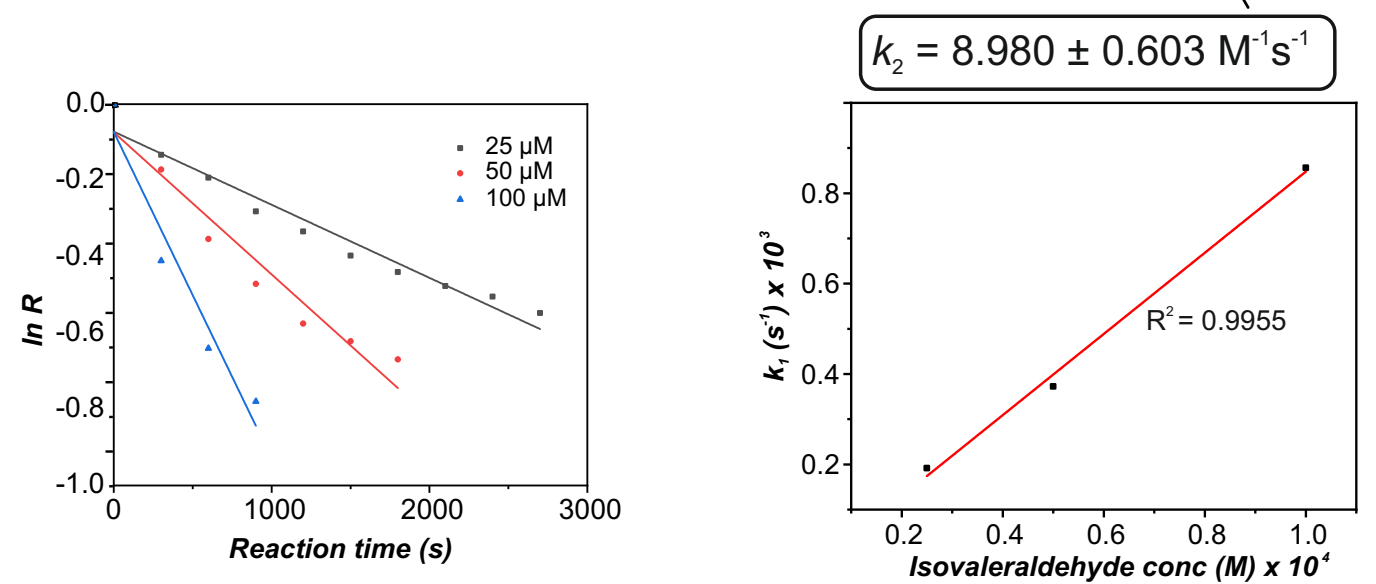

Figure S10. The pseudo first order (Log R vs time) and second order plot ( $k_{1}$ vs [CC]) of the hydrazone conjugation reactions of DMAEH with isovaleraldehyde (7). 


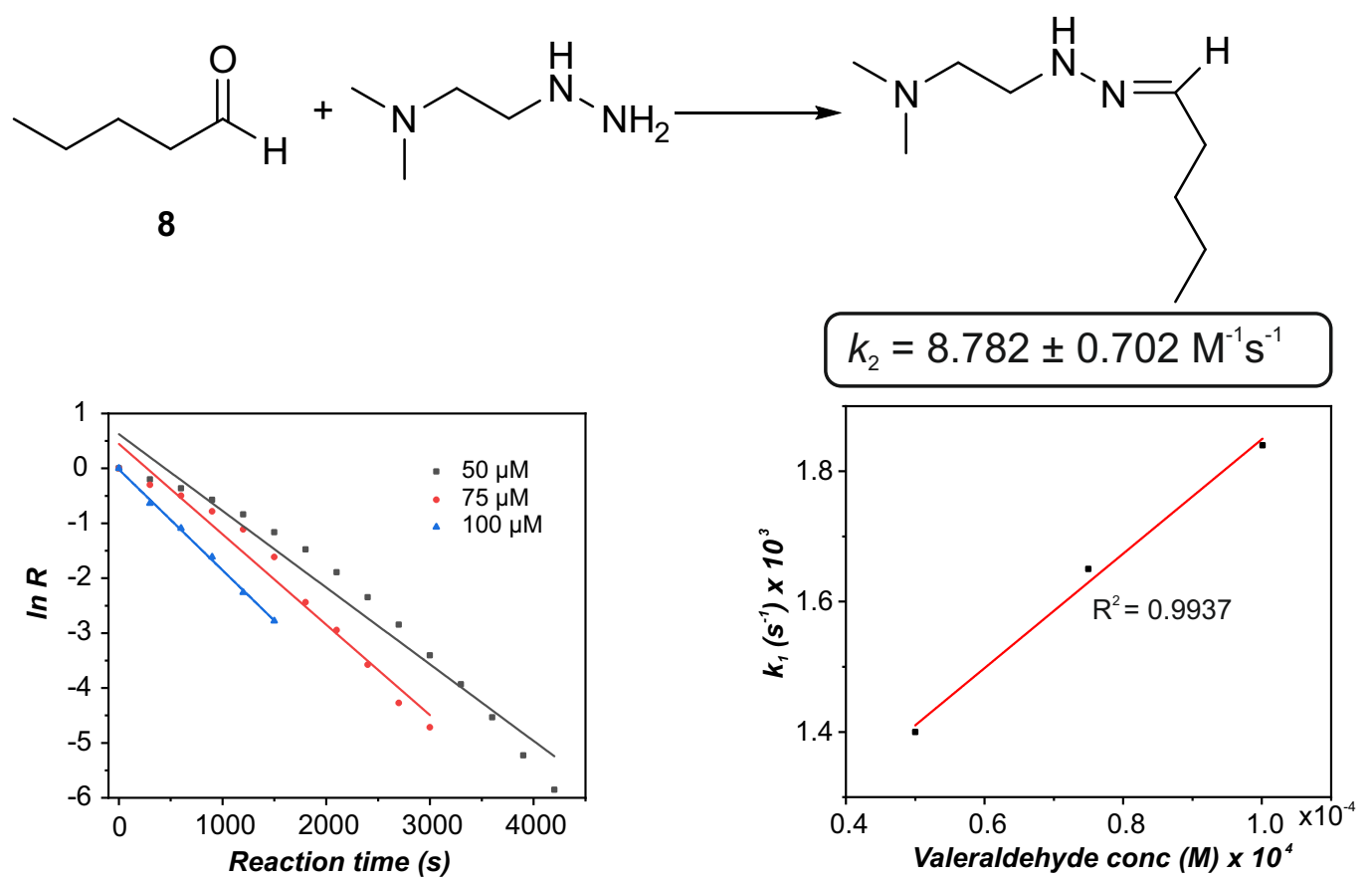

Figure S11. The pseudo first order (Log R vs time) and second order plot ( $k_{1}$ vs [CC]) of the hydrazone conjugation reactions of DMAEH with valeraldehyde (8).<smiles>CN(C)CCNN/N=C/c1ccccc1</smiles>
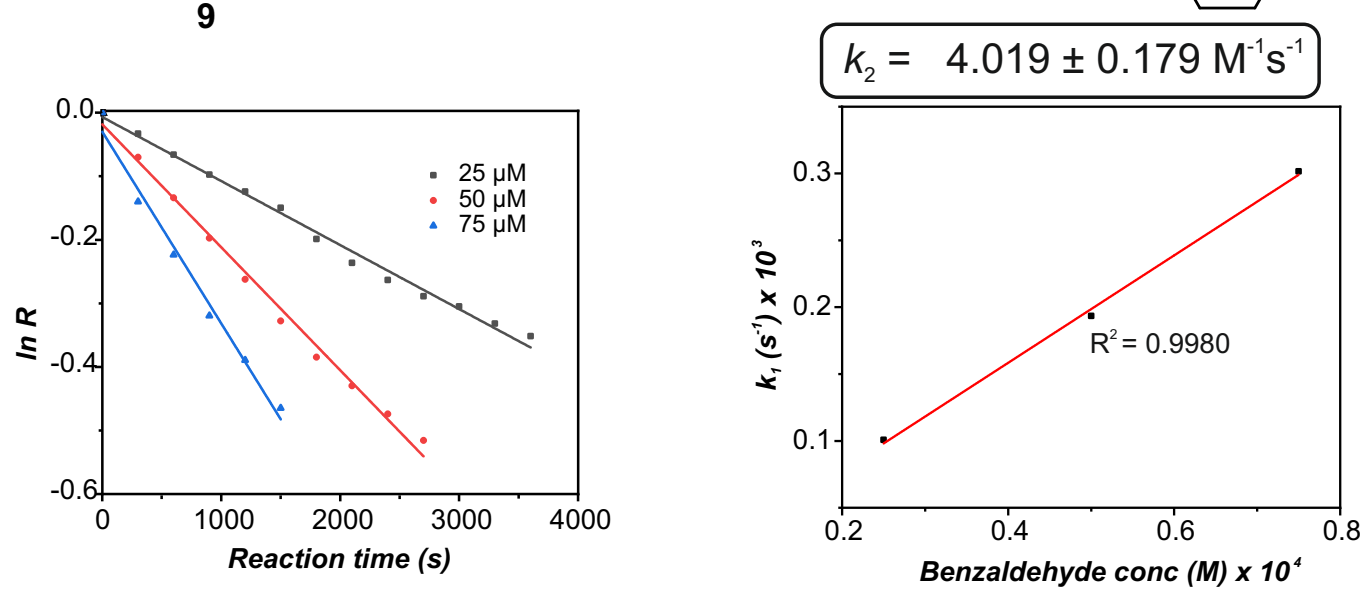

Figure S12. The pseudo first order (Log R vs time) and second order plot ( $k_{1}$ vs [CC]) of the hydrazone conjugation reactions of DMAEH with benzaldehyde (9).
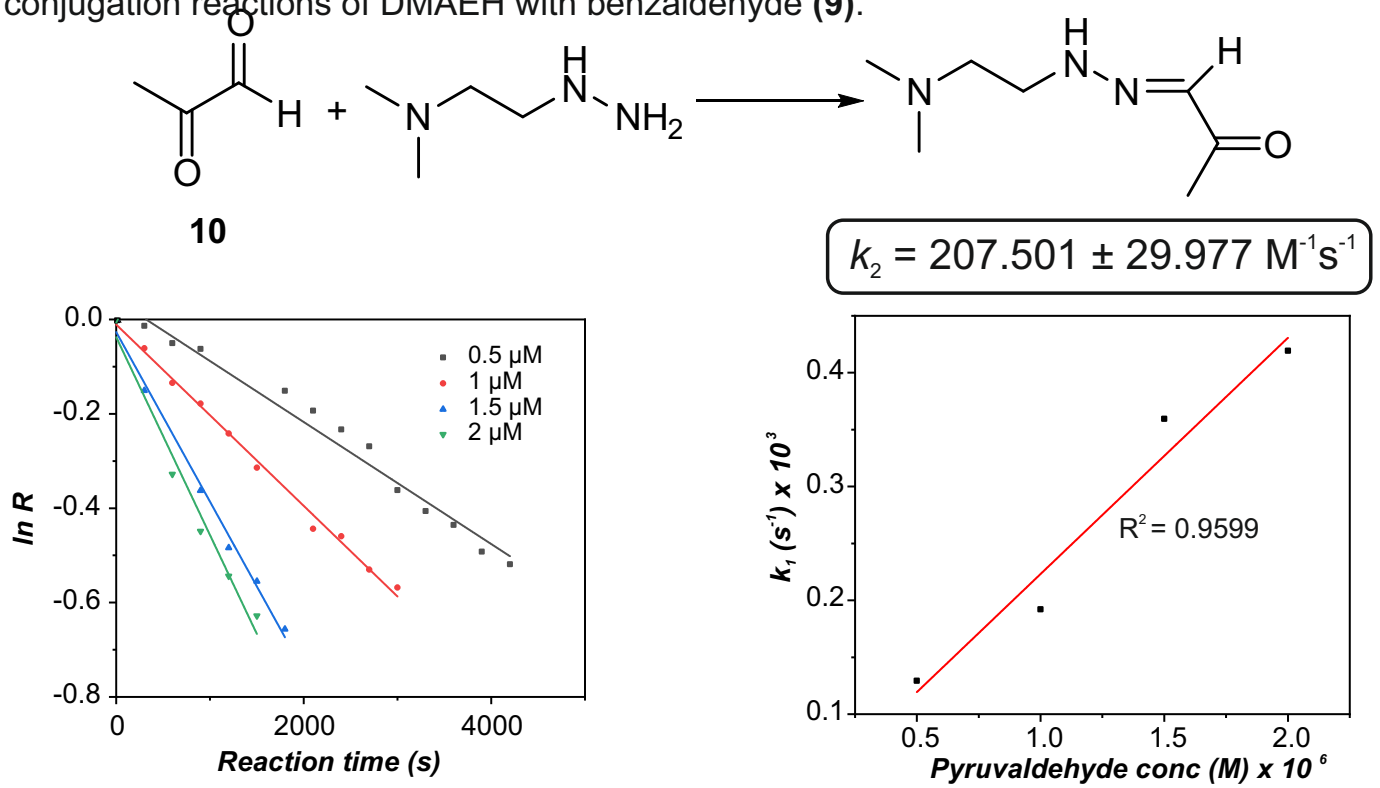

Figure S13. The pseudo first order (Log R vs time) and second order plot ( $k_{1}$ vs [CC]) of the hydrazone conjugation reactions of DMAEH with pyruvaldehyde (10). 

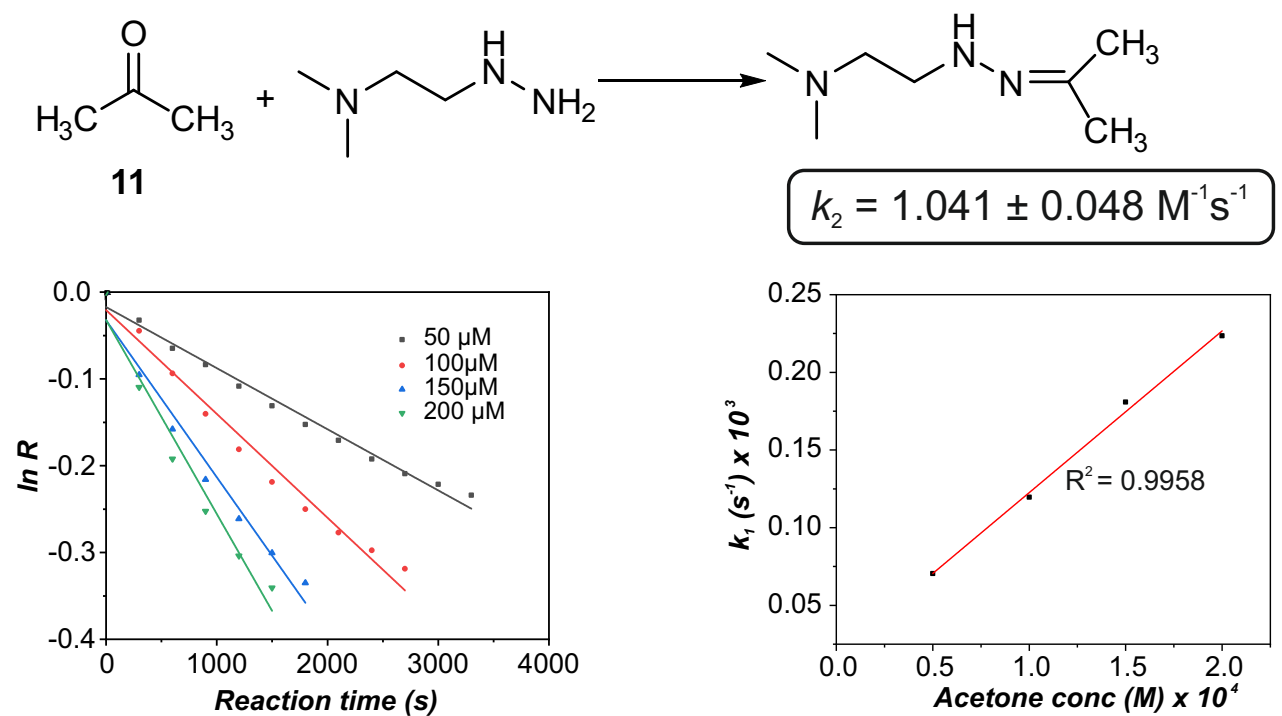

Figure S14. The pseudo first order (Log R vs time) and second order plot ( $k_{1}$ vs [CC]) of the hydrazone conjugation reactions of DMAEH with acetone (11).
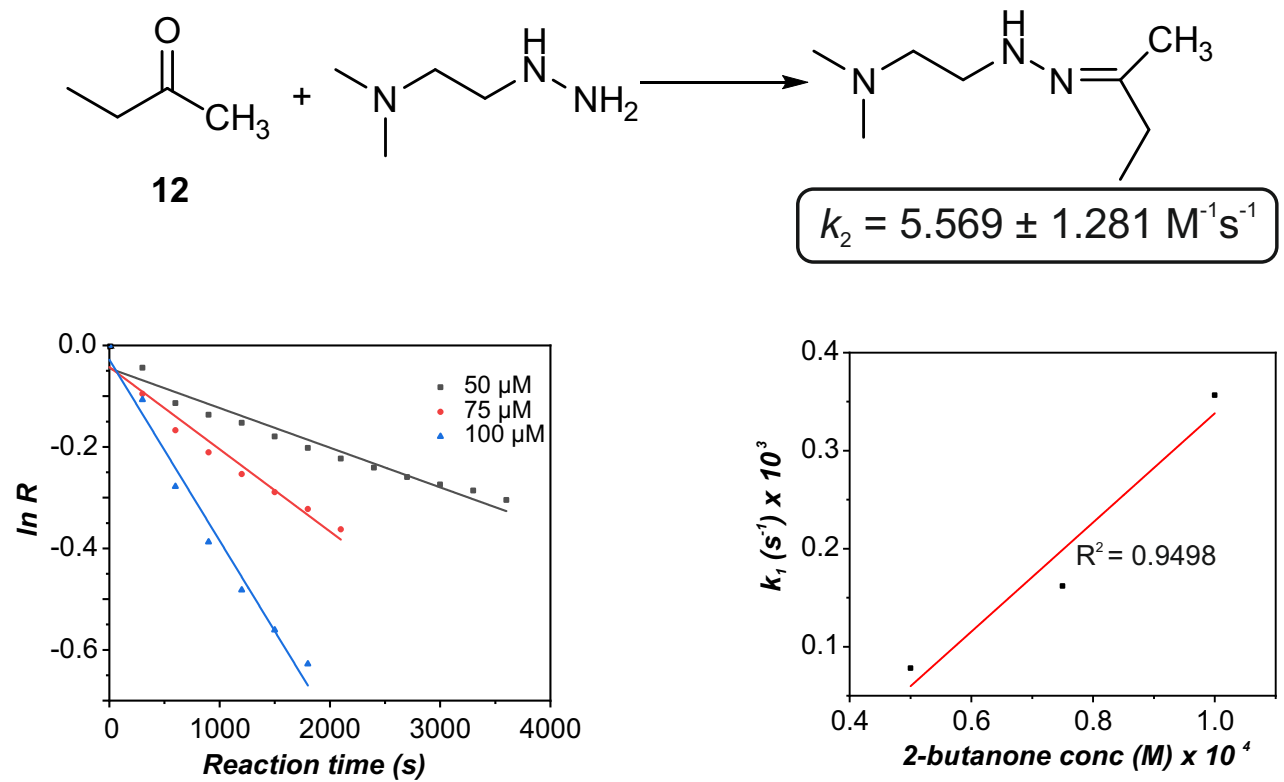

Figure S15. The pseudo first order (Log R vs time) and second order plot ( $k_{1}$ vs [CC]) of the hydrazone conjugation reactions of DMAEH with 2-butanone (12).
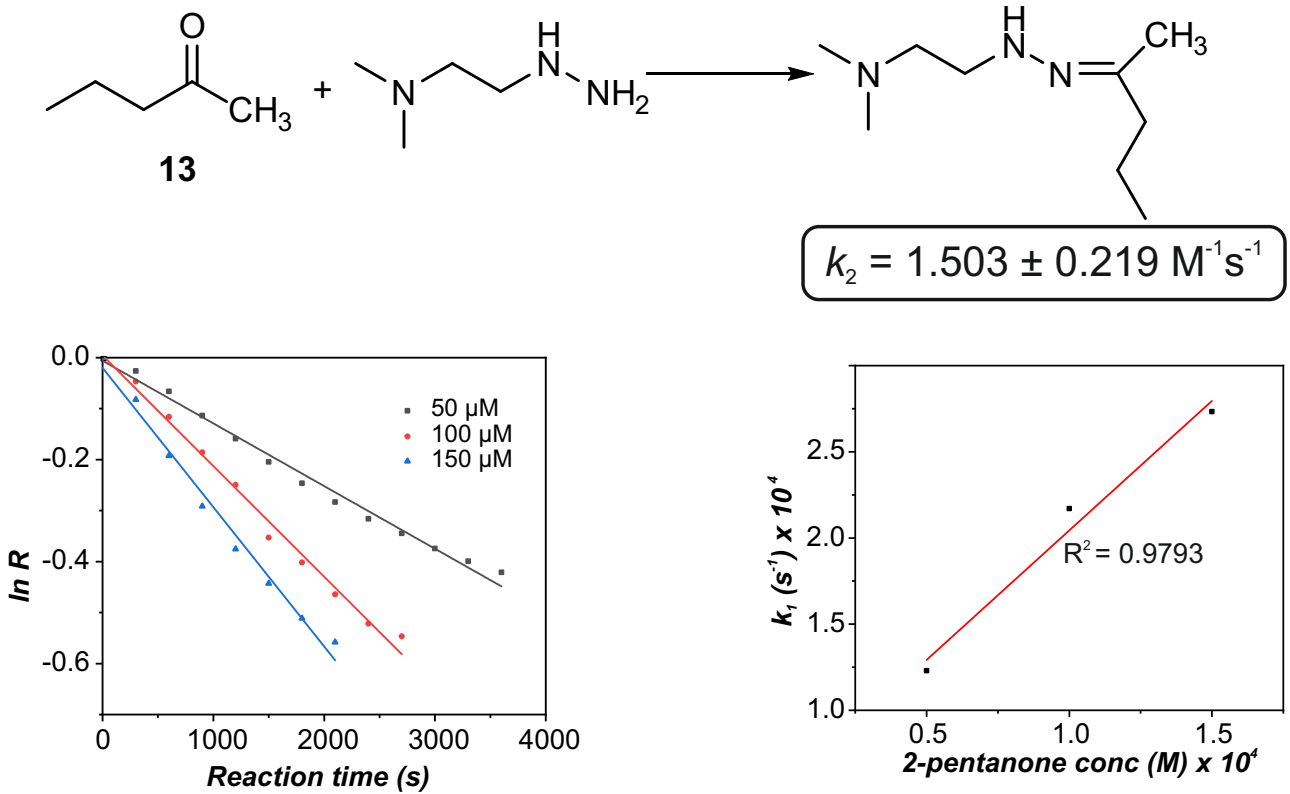

Figure S16. The pseudo first order (Log R vs time) and second order plot ( $k_{1}$ vs [CC]) of the hydrazone conjugation reactions of DMAEH with 2-pentanone (13). 

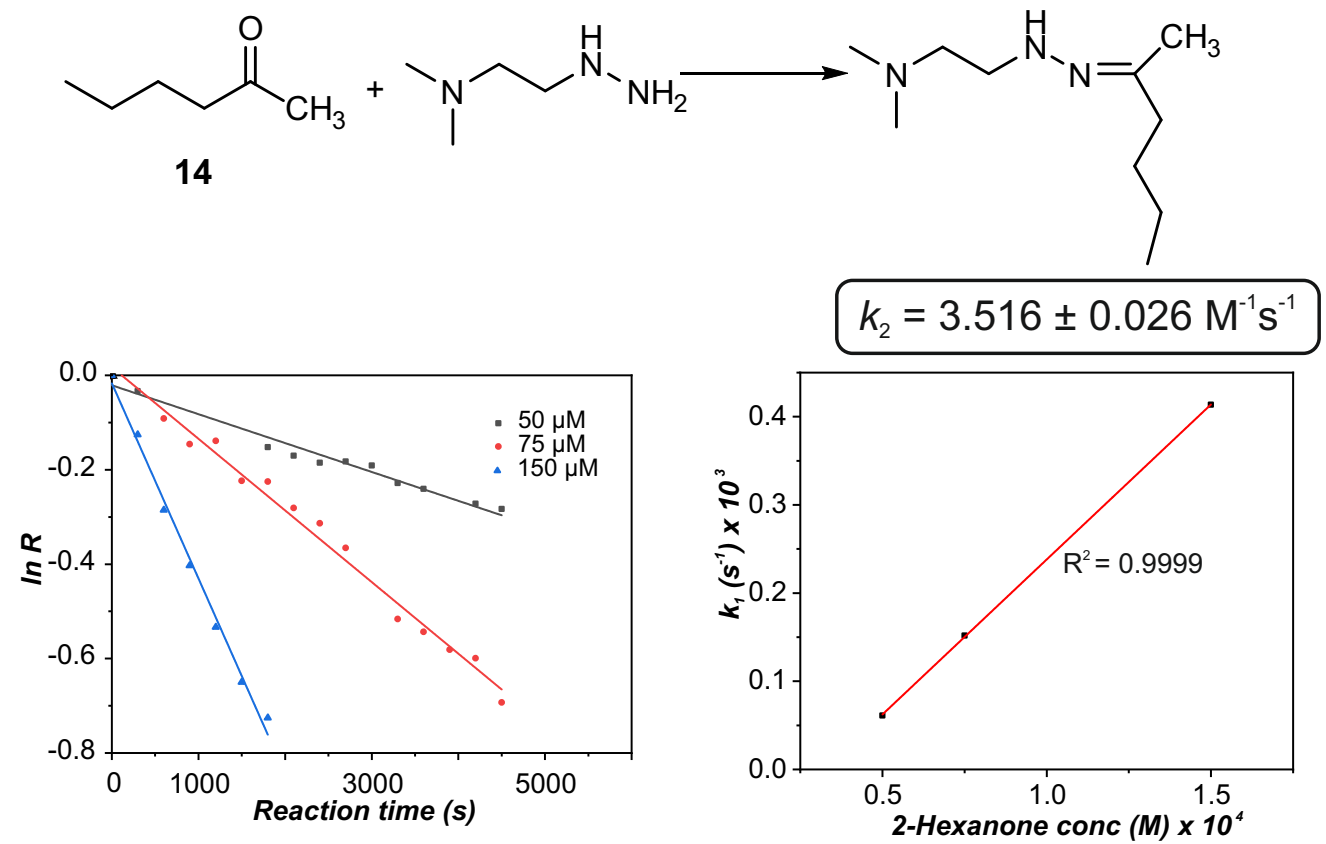

Figure S17. The pseudo first order (Log R vs time) and second order plot ( $k_{1}$ vs [CC]) of the hydrazone conjugation reactions of DMAEH with 2-hexanone (14).
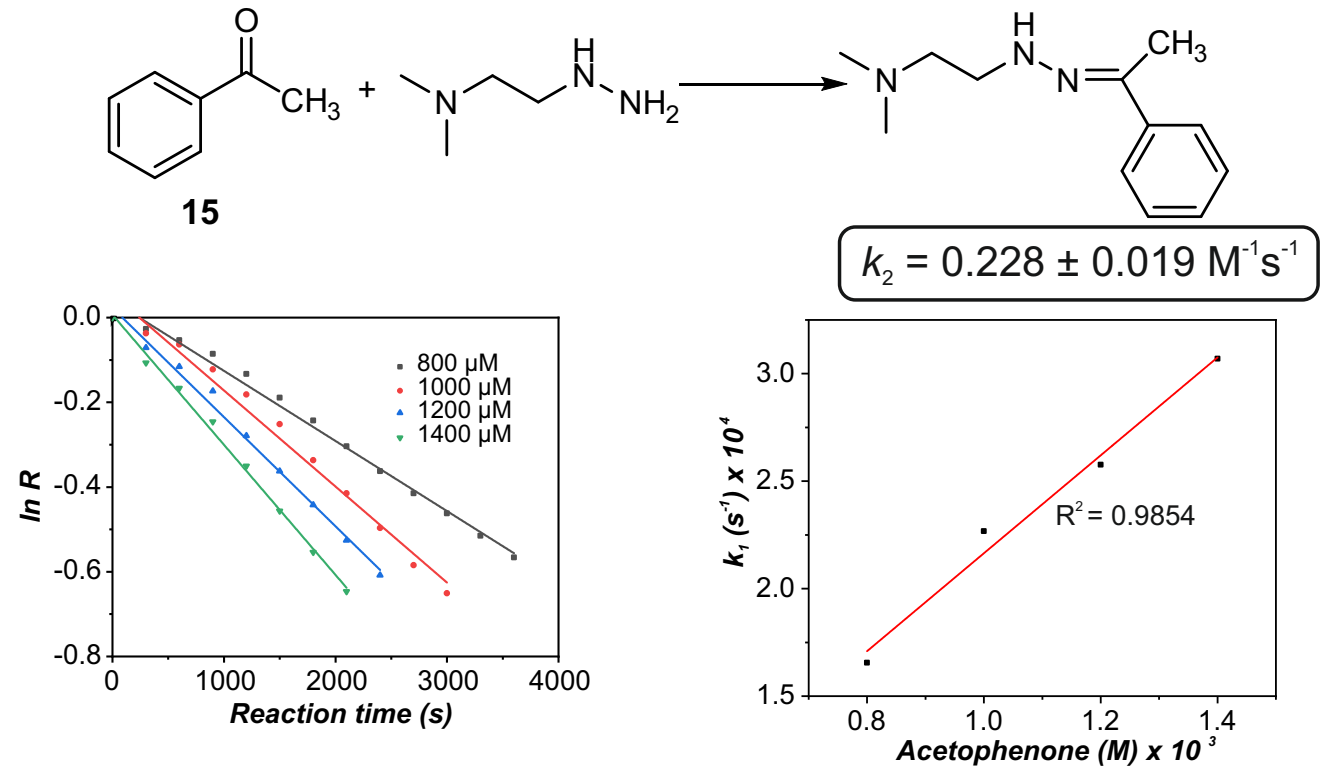

Figure S18. The pseudo first order (Log R vs time) and second order plot ( $k_{1}$ vs [CC]) of the hydrazone conjugation reactions of DMAEH with acetophenone (15).
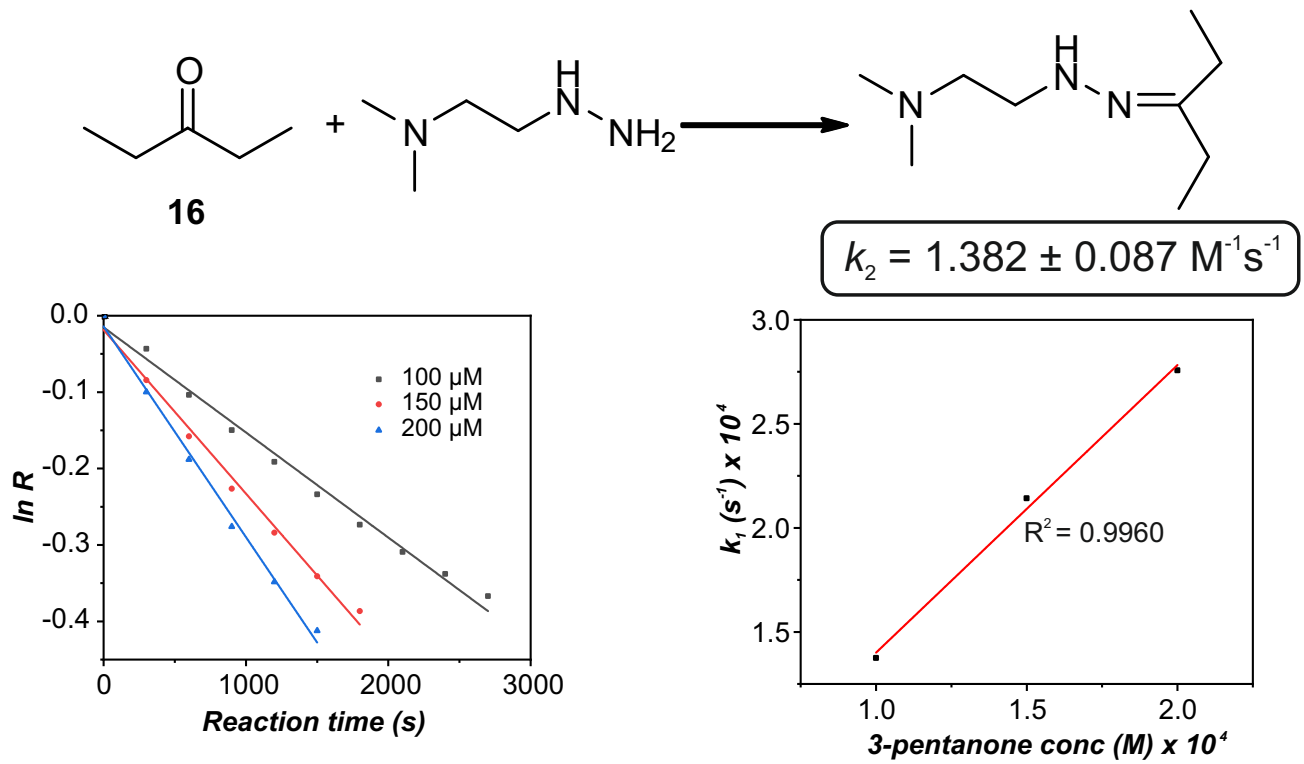

Figure S19. The pseudo first order (Log R vs time) and second order plot ( $k_{1}$ vs [CC]) of the hydrazone conjugation reactions of DMAEH with 3-pentanone (16). 
<smiles>O=CC[C@H](O)[C@H](O)CO</smiles>

17<smiles>CN(C)CCNNCCN(C)CCN/N=C/C[C@H](O)[C@H](O)CO</smiles>

$$
k_{2}=1.325 \pm 0.077 \mathrm{M}^{-1} \mathrm{~s}^{-1}
$$
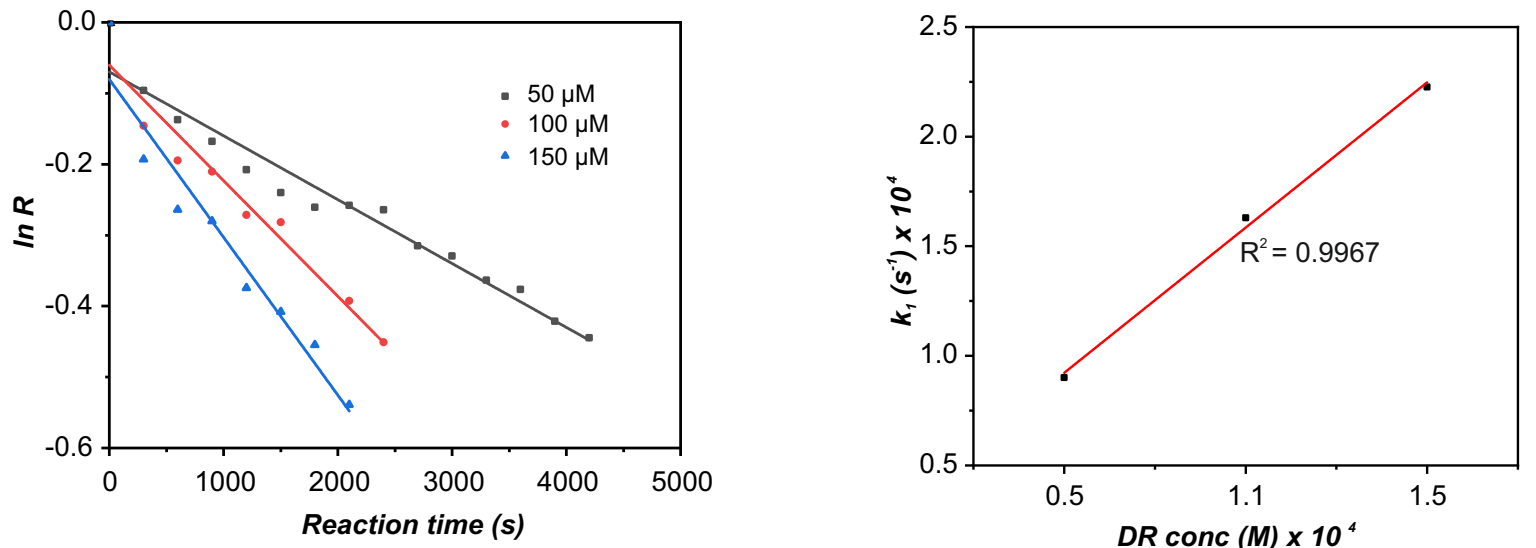

Figure S20. The pseudo first order (Log R vs time) and second order plot ( $k_{1}$ vs [CC]) of the hydrazone conjugation reactions of DMAEH with DR (17).

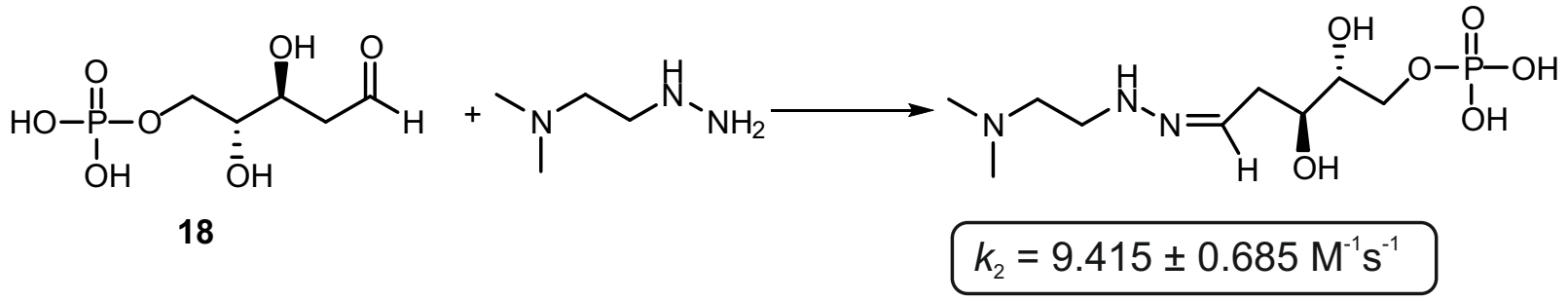
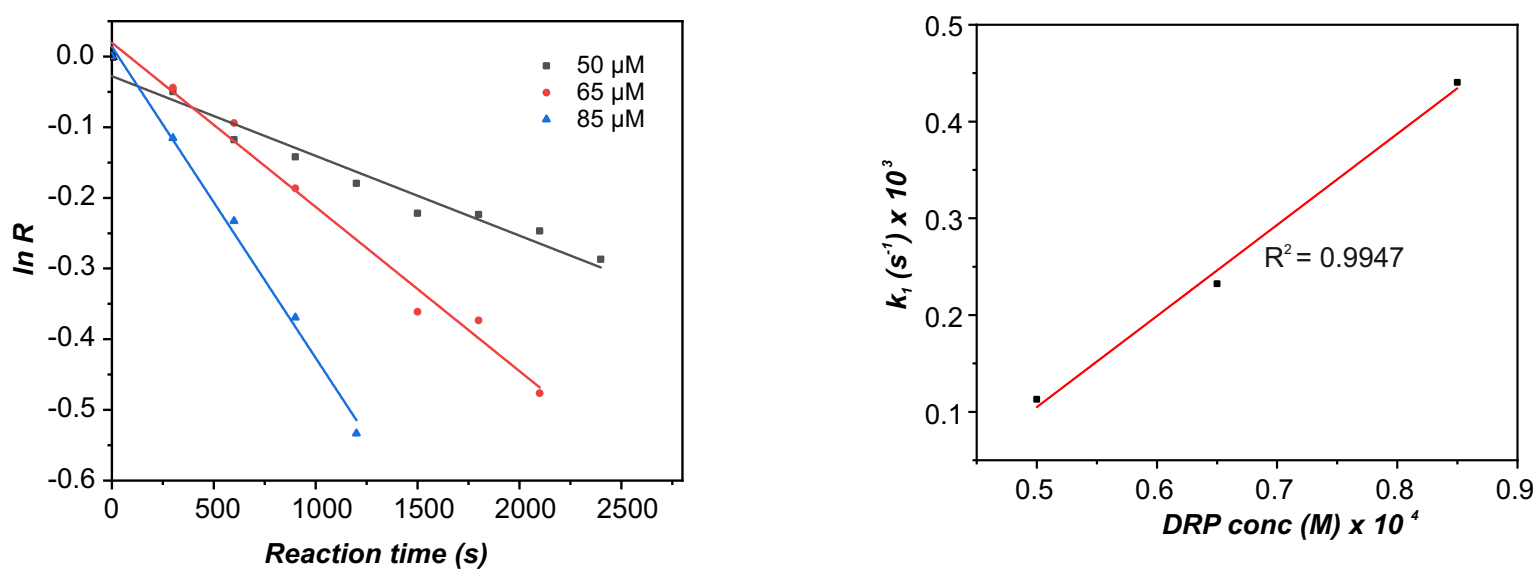

Figure S21. The pseudo first order (Log R vs time) and second order plot ( $k_{1}$ vs [CC]) of the hydrazone conjugation reactions of DMAEH with DRP (18). 


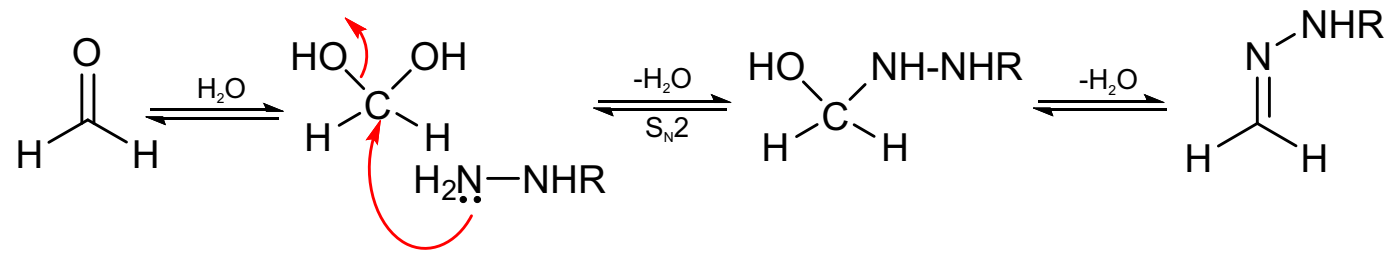

Figure S22. Proposed reaction mechanism for hydrazone formation of formaldehyde

a)

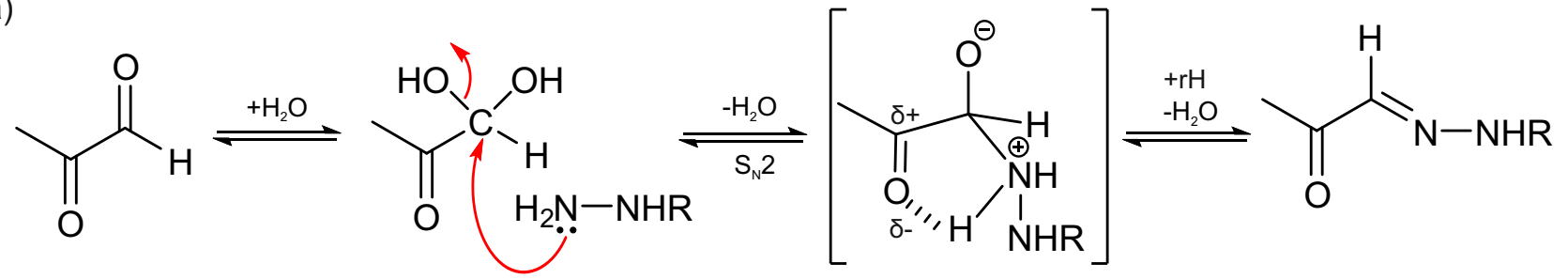

b)

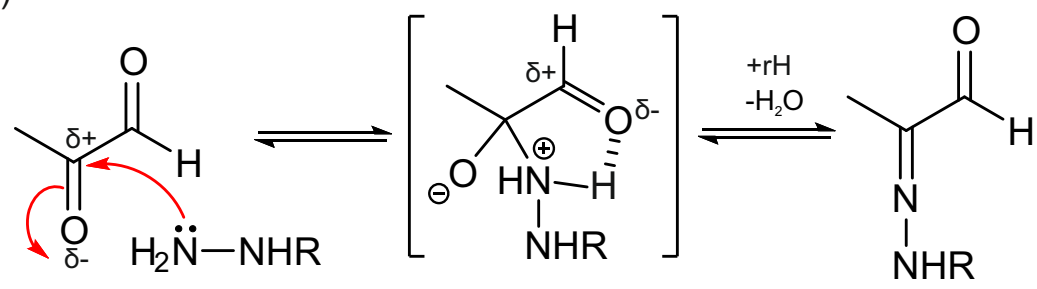

Figure S23. Proposed reaction mechanisms for hydrazone formation of pyruvaldehyde: a) SN2-type, b) nucleophilic addition 